\title{
Sala de Aula Invertida: Recomendações e Tecnologias Digitais para sua Implementação na Educação
}

João Batista Bottentuit Junior

Universidade Federal do Maranhão - UFMA

joaobbj@gmail.com

\begin{abstract}
Resumo: A adoção de modelos mais ativos na sala de aula torna-se uma preocupação no cenário educacional, pois diversas características corroboram para este caminho, entre eles: o perfil diferenciado dos alunos, às demandas do mercado e o desenvolvimento de competências necessárias aos indivíduos no século XXI. Este artigo apresenta através de uma metodologia exploratória e descritiva o modelo de sala de aula invertida, além de aplicativos para dinamização de práticas pedagógicas em interação com o modelo invertido. A combinação de tecnologias e metodologias ativas possibilita aos alunos, além do desenvolvimento de habilidades cognitivas, um maior conhecimento sobre as possibilidades da cultura digital nos seus estudos.
\end{abstract}

Palavras-chave: Sala de aula invertida, Metodologias Ativas, Ensino Superior, Tecnologias de Informação e Comunicação, Aplicativos na Educação.

\section{FLIPPED CLASSROOM: RECOMMENDATIONS AND DIGITAL TECHNOLOGIES FOR ITS IMPLEMENTATION IN EDUCATION}

\begin{abstract}
The adoption of more active models in the classroom becomes a concern in the educational scenario, because several factors corroborate this path, among some of them: the different profile of the students, the demands of the market and the development of competences needed for individuals in the 21ST century. This article presents through an exploratory and descriptive methodology the flipped classroom model, in addition to applications for the dynamization of pedagogical practices in interaction with the inverted model. The combination of technologies and active methodologies enables students, the development of cognitive skills, a greater knowledge about the possibilities of digital culture in their studies.
\end{abstract}

Keywords: inverted classroom, active methodologies, higher education, information and communication technologies, applications in education.

\section{Introdução}

Ministrar uma boa aula, conseguir a atenção e aprendizagem dos alunos é o desejo de todo docente, para este propósito o mesmo tem ao seu dispor vários modelos e estratégias de ensino. Para a adoção de tais modelos é necessário conhecimento, empenho e planejamento, uma vez que, o sucesso estará ligado diretamente ao domínio do conteúdo em sintonia com à adequação a estratégia de ensino, faixa etária e perfil dos alunos envolvidos no processo. Apesar de existir uma diversidade nas formas de ensinar e aprender, muito docentes ainda continuam utilizando as metodologias tradicionais de aula expositiva (ou dialogada), em que os alunos ficam passivamente ouvindo por horas seguidas os conceitos e explicações. De acordo com Rossasi e Polinarski (2011, s/p) "continua presente na educação o agir tradicional, tornando a vivência de sala de aula pouco produtiva. Os alunos fazem o papel de ouvintes, comprovando a não ocorrência de um aprendizado interativo". 
Estes modelos mais tradicionais exploram capacidades de retenção da informação de maneira mais reduzida tais como: o ver e ouvir. Os motivos que levam a perpetuação destes modelos mais tradicionais são variados: a falta de tempo dos docentes para planejar aulas mais dinâmicas, desconhecimento de modelos mais ativos, a replicação dos modelos de formação recebida pelo docente, a falta de infraestrutura física e lógica para realização de experiências, salas superlotadas, falta de incentivo, desmotivação entre outros fatores.

No entanto, refletir sobre estes modelos é uma preocupação dos educadores de um modo geral, pois se observa uma mudança no perfil dos alunos (geração Z, Geração Alpha), que agora são sujeitos mais ativos e que preferem uma aprendizagem mais prática, as novas exigências do mercado que demandam um profissional com alta capacidade de comunicação oral e escrita, que saiba trabalhar em colaboração, que tenha criatividade e pensamento crítico, assim como, observamos a integração na sala de aula de recursos multimídia que permitem uma multiplicidade de possibilidades para mostrar a informação de forma mais atrativa para os alunos, entre outras transformações (NATIONAL EDUCATION ASSOCIATION, 2010).

A partir dos resultados de pesquisas realizadas tanto no Brasil (GOMES et al 2010; SANTOS, 2019) como no exterior (ZAINUDDIN e PERERA, 2019; OTEROSABORIDO ET AL 2018) que atestam a eficácia de modelos ativos na sala de aula, as escolas, centros de formação e universidades começam a progressivamente a refletir sobre metodologias ativas nas salas de aula, desenvolvendo desta forma, altos níveis do domínio cognitivo dos alunos (criar e avaliar), permitindo-os além de exercitarem sua criatividade, a possibilidade do trabalho colaborativo, a reflexão sobre suas aprendizagens, a descoberta através da experimentação, o debate, a concepção de produtos ou soluções sobre os problemas colocados, entre inúmeras outras práticas que fazem com que os conteúdos sejam aproveitados de maneira mais proveitosa.

Se os modelos são bem sucedidos nas formações de curta duração e nas escolas, é nas universidades que estas estratégias têm ganhado maior destaque, uma vez que, os alunos em muitos casos são estudantes e ao mesmo tempo trabalhadores, e chegam às salas de aula, muitas vezes, cansados da jornada diária, e querem modelos que possam ativar seu interesse, além de aplicar a teoria aprendida em situações reais que possam posteriormente levar como experiências para o mercado (GUIMARÃES, 2016).

Pensando nas metodologias ativas aplicadas aos diferentes níveis de ensino surgem às discussões que permeiam este artigo que visa discutir algumas recomendações e ferramentas que o docente poderá aplicar em suas práticas de ensino ativas. Portanto, este estudo de caráter exploratório e descritivo visa perspectivar formas, modelos e ferramentas para práticas pedagógicas ativas.

\section{Metodologias Ativas}

Os modelos ativos na educação visam reverter à idéia do sábio no palco (sage on the stage) para o modelo do guia ao lado (guide on the side). Esta mudança implica em transformações na sala de aula, modificando o seu layout de cadeiras enfileiradas para um modelo que comporta várias estações de trabalho colaborativo (ver figura 1). 


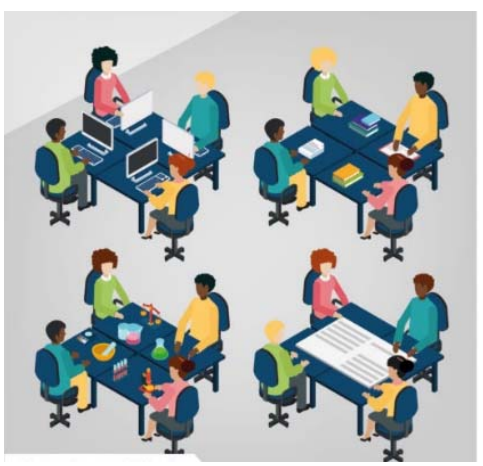

Figura 1: Sala de aula para metodologias ativas

Fonte: Adaptado de: http://www.foreducationedtech.com.br/edtech-news/ensinohibrido/

Segundo Bacich e Moran (2018, p.3) “a aprendizagem mais profunda requer espaços de prática frequentes (aprender fazendo) e de ambientes ricos em oportunidades”. Permitindo desta forma um espaço perfeito para a discussão, planejamento, construção e criação de respostas para os desafios propostos nas aulas, transformando a sala em espaços de interação, pesquisa e desenvolvimento.

Existem vários modelos de metodologias ativas com experiências em vários níveis de ensino, que se bem planejadas e aplicadas, podem promover praticas pedagógicas interessantes. Entre estes modelos temos:

Aprendizagem baseada em problemas (problem based learning) é uma metodologia que coloca os alunos em grupo para que juntos solucionem problemas que envolvam os conceitos e teorias anteriormente aprendidos. Desta os alunos discutem e chegam às melhores respostas para os problemas colocados. De acordo com Ribeiro (2008, p.8)

"é uma metodologia de ensino e aprendizagem com larga utilização em escolas superiores (notadamente de medicina) e em outros níveis educacionais. Concebido no final dos anos 1960, o PBL, e emprega problemas da vida real (reais ou simulados) para iniciar, motivar e focar a aprendizagem de conhecimentos conceituais, procedimentais e atitudinais."

Aprendizagem baseada em projetos (project based learning) é uma metodologia que pretende auxiliar na compreensão dos conteúdos através de fases que vai deste a ideia até a apresentação de um produto/resposta final. Para uma melhor compreensão os projetos podem ser divididos em etapas sendo estas: 1) conhecimento sobre o tema a desenvolver o projeto; 2) planejamento sobre como o produto ou solução será desenvolvida; 3) execução/construção do produto ou solução; 4) avaliação da concepção e 5) apresentação. De acordo com Masson et al (2012, p.4) esta metodologia visa "estimular no aluno a capacidade de aprender a aprender, de trabalhar em equipe, de ouvir outras opiniões (mesmo que contrárias às suas), induzindo-o a assumir um papel ativo e responsável pelo seu aprendizado".

Aprendizagem baseada em jogos (game based learning) é uma metodologia que pretende adotar de jogos educativos na sala de aula, através destes recursos eles podem exercitar a capacidade de trabalhar em colaboração, discutir estratégias, negociar melhores caminhos, bem como desenvolver outras habilidades. Nesta perspectiva, ao serem desafiados podem aprender de maneira lúdica e estimulante, desafiado-os a cumprir metas e ultrapassar barreiras e vencer suas limitações. Para Silva; Müller e Bernardi (2011, p.4),

O ciclo do jogo consiste na interação do estudante com sistema que inclui as decisões ou reações do mesmo (como diversão ou interesse), seu 
comportamento (como maior persistência ou tempo na tarefa) perante essas decisões tomadas e o feedback do sistema que, consequentemente, desencadeia novamente o ciclo. Com a interação e o engajamento do estudante no jogo ele alcança os objetivos educacionais e o ciclo termina com resultados de aprendizagem.

Gameficação (gamefication) esta metodologia é muitas vezes confundida com a adoção de jogos em sala de aula, no entanto, ela pretende adotar as mecânicas dos jogos para motivar os alunos para a aprendizagem, desta forma os alunos se transformam em personagens que deverão desbravar a sala de aula como cenário na execução das fases, desafios, e metas a fim de conseguirem as recompensas, mas sempre atentos as possíveis perdas e punições. Ao final do processo os alunos se envolvem na tarefa e a aprendizagem acontece de maneira divertida e prática. Para Fardo (2013, p.3)

A gameficação se apresenta como um fenômeno emergente com muitas potencialidades de aplicação em diversos campos da atividade humana, pois a linguagem e a metodologia dos games são bastante populares eficazes na resolução de problemas (pelo menos nos mundos virtuais) e aceita naturalmente pelas atuais gerações que cresceram interagindo com esse tipo de entretenimento, ou seja, a gameficação se justifica a partir de uma perspectiva sociocultural.

Entre outros modelos temos o design thinking que preocupa-se em refletir sobre uma situação problema de maneira colaborativa a fim de solucioná-la através da discussão, negociação e proposições de idéias ou soluções. É uma metodologia ativa e bastante prática para resolução de problemas e a concepção de projetos, uma vez que ela promove a inovação ao abrir um espaço para a concepção de novas ideias. "É permissiva a falhas e a aprendizagem com os próprios erros, viabilizando o surgimento de novas ideias centrasse na pessoa, pois inicia pela compreensão das necessidades e motivações dos envolvidos” (SPAGNOL, 2017,p.73).

Além dos modelos acima citados temos ainda outras metodologias como: o aprendizado baseado em times (Team Based Learning), a instrução por pares (Peer Instruction) e a metodologia que será discutida com maior detalhamento no próximo tópico, a sala de aula invertida (Flipped Learning).

Entre todos os modelos ativos apresentados, observa-se algo comum a todos eles, a preocupação em envolver os indivíduos, em processos de discussão e colaboração, para que tenham a oportunidade de falar sobre os conteúdos durante as aulas, ou seja, quando colocamos mais sentido no processo de aprendizagem ela se torna mais efetiva. Ao falar, escrever, ouvir, esquematizar e ensinar os colegas atinge-se, um nível bem mais elevado de compreensão, em face da simples leitura silenciosa de um texto, ou apenas assistir a uma aula, por exemplo.

\section{Sala de Aula Invertida}

O modelo de sala de aula invertida ou Flipped Classroom foi proposto por Jonathan Bergmann e Aron Sams, dois professores Norte Americanos que inicialmente começaram a gravar aulas e vídeos (com auxílio de programas de capturas de telas) para disponibilizar materiais educativos aos alunos que faltavam as suas aulas. Com o passar do tempo, começaram a observar um melhor rendimento dos mesmos, e em pouco tempo os vídeos se popularizaram na escola, fazendo sucesso também com alunos que frequentavam as aulas de maneira regular, desta forma, decidiram aproveitar o tempo de sala de aula com atividades práticas e deixar toda a teoria para que os alunos estudassem em casa através dos vídeos. (BERGMANN e SAMS, 2012). 
A estratégia se tornou um sucesso, fazendo com que o aproveitamento em sala de aula e os rendimentos dos alunos, aumentassem de forma exponencial. Daí surgiu o conceito de sala de aula invertida, ou seja, o que frequentemente os alunos fazem em sala de aula (estudam a teoria) agora passam a fazer em casa, e o que costumavam fazer em casa (as tarefas), agora fazem dentro de sala de aula, através de atividades mais desafiadoras e colaborativas, onde as práticas são realizada de maneira diversificada, com a utilização de jogos, cases, projetos, atividades laboratoriais, entre outros, (BERGMANN e SAMS, 2016).

Vários são os autores que tentam conceituar a sala de aula invertida, no entanto, existe um conceito que melhor reflete a metodologia, e foi proposto pela Flipped Learning Network (2014, s/p, tradução do autor) quando afirmam que:

\begin{abstract}
A aprendizagem invertida é uma abordagem pedagógica na qual a instrução direta se desloca do espaço de aprendizagem grupal para o espaço de aprendizagem individual, e o espaço grupal resultante é transformado em um ambiente de aprendizagem interativo e dinâmico em que o educador guia os alunos enquanto eles aplicam os conceitos e se engajam criativamente no assunto.
\end{abstract}

A organização do modelo (ver quadro 1) segue um padrão lógico que pretende oferecer aos alunos oportunidade para a construção dos saberes necessários a execução de tarefas práticas em sala de aula bem como a verificação de suas aprendizagens após as intervenções práticas (TALBERT, 2019):

\begin{tabular}{|c|c|c|}
\hline Antes da Aula & Durante a aula & Depois da aula \\
\hline $\begin{array}{l}\text { O professor planeja aulas } \\
\text { através de ferramentas } \\
\text { digitais, ou de materiais } \\
\text { educativos de modo com } \\
\text { que os alunos possam } \\
\text { estudar e compreender os } \\
\text { conceitos envolvidos com } \\
\text { os conteúdos. }\end{array}$ & 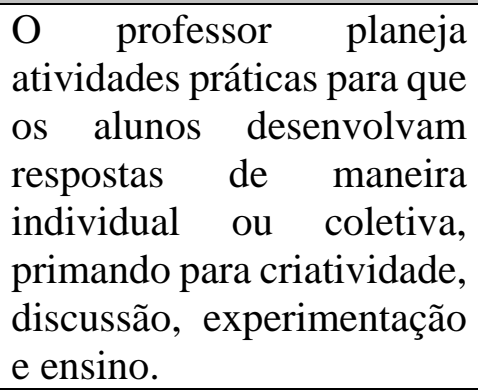 & $\begin{array}{l}\text { Os alunos recebem testes } \\
\text { abertos, fechados ou mistos } \\
\text { para verificação das suas } \\
\text { aprendizagens através das } \\
\text { metodologias utilizadas. }\end{array}$ \\
\hline
\end{tabular}

\title{
Quadro 1: Organização didática da sala de aula invertida
}

Apesar do esquema, parecer simples, faz-se necessário a preparação do professor, o planejamento e o diagnóstico da turma para desenhar as atividades e selecionar as tecnologias que melhor irão se ajustar ao público. Quando não se tem este cuidado, muitos são os projetos de sala de aula invertida que fracassam, em função de vários fatores entre eles:

- O pouco entendimento/compreensão do modelo de sala de aula invertida, ou seja, tentar implementar o mesmo antes da sua exata compreensão;

- Falta de adaptação dos materiais didáticos para o modelo de sala de aula invertida, uma vez que, os capítulos de livros, são pensados para um ensino presencial e no modelo invertido, a construção dos conhecimentos conceituais ocorre na casa dos alunos, portanto, a linguagem dos materiais didáticos deve ser dialogada e adequada ao público, assim como torna-se relevante variar nos recursos, para além do texto, deve-se incluir, áudio, vídeo, animações, simulações, etc.

- Salas superlotadas e não adequadas ao trabalho em grupo, falta de conectividade entre outras limitações físicas. 
- Falta de feedback do docente durante a realização das atividades práticas em sala de aula, mesmo com atividades interessantes e com detalhamento das fases de execução é fundamental que sejam supervisionados os grupos na tentativa de incentivo aqueles menos participativos, ou mesmo dando suporte e encaminhamento na resolução dos desafios propostos.

Segundo Valente (2019) algumas regras são importantes para o sucesso da sala de aula invertida, entre elas: envolver questionamentos na execução da aula, resolução de problemas e outras atividades ativas que permitam aos alunos relembrar os conhecimentos aprendidos e ampliar as capacidades, além disso, receber feedback durante a execução das tarefas, incentivar a realização de atividades online e presenciais, valorizar a participação e o cumprimento das tarefas, e por fim, estruturar o material de maneira bem clara e organizada de modo com que minimizem as dúvidas e oportunize maior autonomia individual ou em grupo.

Para dinamizar as práticas de sala de aula invertida faz-se necessário a adoção de Tecnologias Digitais de Informação em comunicação (TDIC) elas funcionam como pontes entre os docentes e os conteúdos a serem trabalhados. Além de vídeo aulas seria conveniente ter uma Ambiente Virtual de Aprendizagem (AVA) que poderá ser o Moodle (acrônimo de Modular Object-Oriented Dynamic Learning Environment), o Edmodo (plataforma de comunicação e colaboração, e disponibilização de conteúdos) ou mesmo um blog onde o material da disciplina possa ser disponibilizado e organizado de maneira planejada.

\section{Sites/Aplicativos para incrementar as práticas de sala de aula invertida}

Além das tecnologias mencionadas no tópico anterior, é relevante a adoção de tecnologias móveis como aliadas nos processos. É inegável, afirmar que todas as áreas do conhecimento se beneficiaram com o aparecimento das tecnologias móveis e, sendo a educação um dos principais pilares sociais, também tirou ou deveria ter tirado seu partido, permitindo ao aluno e ao docente o acesso a um conjunto amplo de recursos informacionais importantes, e necessários, às suas formações.

Sendo que a cada dia mais e mais recursos surgem para atender a demanda e as múltiplas necessidades dos professores e alunos. Entre estes recursos temos os aplicativos educacionais que são desenhados especificamente para determinadas áreas, conteúdos ou disciplinas, além destes temos os aplicativos genéricos que podem ser adaptados/utilizados em diferentes contextos (WhatApp, por exemplo).

O uso destes dispositivos contribui numa maior estimulação das atividades significativas, assim como podem ser combinados com diversas estratégias didáticas que ajudam no desenvolvimento de habilidades importantes aos alunos do século XXI. Afinal, pode-se se tratar "de um terreno fértil para práticas e discursos enquanto práticas sociais, para fazer e comunicar significados, altamente criativas” (GOUNARI, 2009, p. 22).

Na sala de aula o celular é a tecnologia móvel mais acessível aos alunos, pois com diversidade de marcas e modelos no mercado, seu valor torna-se relativamente acessível, e alguns alunos já o trazem para sala de aula como uma ferramenta de consulta a materiais educacionais ou mesmo para realizar comunicação. No entanto, ainda existe certa resistência, por parte de alguns educadores em aceita-lo, alguns por desconhecimento das suas potencialidades, acabam por considerá-lo uma ferramenta de distração. No entanto, existem vários aplicativos que podem potencializar experiências significativas em sala de aula, entre eles:

\section{Nearpod (http://nearpod.com)}


Trata-se de um site com propósito de melhorar a interação nas aulas/apresentações que utilizam slides. Ou seja, é um sistema multiplataforma (acessível em computadores e dispositivos móveis) que permite por um lado, enriquecer os slides com: vídeos, tarefas (quizes, múltipla escolha, preenchimento de espaços em branco, acesso a recursos multimídia, etc.); e por outro lado, a interação dos alunos a todos estes recursos através de seus dispositivos móveis (celulares, tablets ou notebooks), transformando-os de instrumentos de distração para ferramentas de trabalho e produção do conhecimento em sala de aula.

O Nearpod assim como outros aplicativos permite como que o aluno saia da posição passiva de apenas absorver o que o professor ensina para uma postura mais ativa, pois, caso o professor faça um bom planejamento de aula, com uso de recursos disponíveis no aplicativo, o aluno poderá interagir em diversos momentos da aula, através das respostas aos desafios que vão sendo colocado entre os slides e que o aluno precisa responder a cada um deles. Neste modelo a turma se torna muito mais participativa, pois precisam prestar atenção na aula para dar respostas aos quizes e questionamentos que vão sendo disponibilizados em tempo real pelo professor (FEITOSA FILHO et al 2018; MOURA, 2015).

\section{Kahoot (http://kahoot.com)}

O Kahoot é um site multiplataforma que permite a criação de perguntas em formato variado (quiz, jumble e survey) para verificação da aprendizagem em tempo real, tornouse mais popular e conhecido pela modalidade Quiz, onde os docentes além de estabelecerem perguntas, podem temporizá-las, tornando a avaliação mais dinâmica e incentivando um raciocínio mais rápido. O docente poderá criar perguntas acessando ao site do Kahoot e dinamizar as questões através do uso dos dispositivos móveis dos alunos aproveitando desta forma a estratégia de utilização dos dispositivos dos alunos nas práticas pedagógicas (BYOD - Bring your on device).

Já existem vários artigos publicados (BOTTENTUIT JUNIOR, 2017; PLUMP e LAROSA, 2017) que atestam sua eficácia em diferentes níveis de ensino tornando um recurso a ser utilizado tanto para uma avaliação diagnóstica (de conhecimentos prévios), tal como, um mecanismo de avaliação pós-aula (verificação da aquisição de conhecimento). Na sala de aula invertida, este aplicativo mostra-se eficaz e atrai a atenção dos alunos sendo possível a utilização individual ou em grupo, para engajamento e aumento da motivação dos participantes.

\section{Edpuzzle (http://edpuzzle.com)}

Os vídeos e filmes são recursos utilizados em sala de aula a bastante tempo, no entanto, em alguns casos o docente desiste de utilizar o recurso por falta de tempo no planejamento (para passar um filme de 2 ou 3 horas de duração), ou mesmo, infraestrutura para a disponibilização do filme. Neste sentido, o aplicativo Edpuzzle permite a dinamização de vídeos didáticos para os alunos através de múltiplas plataformas. Para tal propósito o docente deverá acessar o site do aplicativo, escolher um vídeo/filme (disponível online através do You Tube, Khan Academy, etc., ou upload do vídeo desejado), em seguida fará acréscimos como, por exemplo: notas de áudio ao longo dos vídeos, modificação do áudio, exercícios (perguntas abertas ou múltipla escolha). Com isto, os alunos podem assistir aos vídeos e filmes em qualquer tempo e espaço geográfico, ficando as respostas dadas a cada pergunta registradas para posterior consulta e correção do docente (COSTA, MONTEIRO e BOTTENTUIT JUNIOR, 2018).

\section{Sli.do (https://www.sli.do/)}


Trata-se de um site concebido para interação direta com o público, ou seja, serve para que o docente/palestrante ou apresentador possa receber feedback em tempo real do seu público (ou alunos). As interações podem ser realizadas através de perguntas enviadas pelos participantes, ou ainda respostas (curtas/longas ou múltipla escolha) ou palavras chaves (que se transformam em nuvens de ideias). Como vantagens pode-se destacar: a possibilidade de interação em tempo real e a construção de conhecimento de maneira partilhada, a oportunidade anônima de envio de respostas/comentários (para que aqueles mais tímidos possam manifesta sua opinião ou resposta de forma mais rápida e natural), além da possibilidade de projetar na tela (durante a aula) os resultados de uma sondagem pública, de um questionário, ou de um conjunto comentários dado a um assunto polemico com a possibilidade de baixar e guardar os arquivos obtidos.

Como desvantagem aponta-se a questão da semi-gratuidade, ou seja, até três tipos de tarefas o site é gratuito, caso o usuário deseje utilizar mais que este número de questões, é necessário pagamento de licença (mensal/anual) para uso de maneira mais ampla. Apesar de ter sido projetado para eventos ele pode ser muito útil em sala de aula, e não é necessário baixar o aplicativo no dispositivo móvel, ou seja, é tudo online, convertendose numa ferramenta tanto de interação quanto de coleta de dados.

\section{Plickers (https://www.plickers.com/)}

Trata-se de um site que permite a criação de avaliação interativa em tempo real em sala de aula, para tal efeito, o aplicativo/site permite criar perguntas e respostas de múltipla escolha que serão respondidas pela turma (previamente cadastrado no site) com auxílio de cartões gerados pelo site e lidos por um aparelho celular. Ao acessar o aplicativo, o docente faz a leitura dos cartões e verificar via app às respostas certas e erradas, além de divertida a plataforma tem a grande vantagem de minimizar a infraestrutura tecnológica necessária, uma vez que somente o docente necessita de acesso a internet e posse de dispositivo móvel para a leitura dos cartões (físicos) e acesso a aplicação. Aspecto este que pode ser decisivo para sua adoção, na medida em que, algumas instituições de ensino ainda são carentes de acesso à Internet de qualidade (COSTA, DUAILIBE, e BOTTENTUIT JUNIOR, 2018).

Estes são apenas algumas sugestões de aplicativos que podem auxiliar o docente a dinamizar suas estratégias de sala de aula invertida uma vez que em muitos casos os mesmos querem inovar suas práticas, no entanto, desconhecem de ferramentas práticas para os momentos de sala de aula, ou mesmo as sondagens pós-aula. Carvalho (2015) aponta que os aplicativos podem ser divididos em categorias tais como: a) Sondar e testar (Edpuzzle, Socreative, Gosoapbox, Educaplay, etc.); Representar o conhecimento: (Nearpod, Powtoon, mindmap, etc.), Desafiar a aprender (Plickers, Kahoot, Sli.do, Habitica, etc.).

\section{Considerações Finais}

Cabe a todos os profissionais envolvidos com a educação repensar as práticas pedagógicas e metodologias utilizadas para a construção do conhecimento, uma vez que Talbert (2019 p.7) já nos alerta que "o modelo tradicional cria dependências intelectuais indesejadas dos alunos em relação aos professores”. Se o desejo da sociedade é formar jovens autônomos como altas habilidades em raciocínio lógico, com capacidade investigativa, criativos e habilidosos na resolução de problemas, então não podemos repetir fórmulas que já sabemos o resultado. $\mathrm{O}$ atual momento, demanda uma formação que prepare os indivíduos para criar soluções inovadoras, com capacidade crítica e reflexiva, portanto as metodologias ativas (se bem planejadas) podem contribuir para o processo na medida em que oportunizam uma maior prática na execução de tarefas e 
produção dos conhecimentos, saindo dos modelos passivos e monótonos de aprendizagem para um modelo que permite aos sujeitos a concepção de respostas imediatas para problemas do quotidiano e que podem perfeitamente ser reutilizadas ou recombinadas em novos contextos de vida.

Muitos são os modelos e cada um deles explora uma vertente diferenciada da prática e não existe um modelo ideal, na medida em que é necessário conhecer os alunos para que se possa adotar a melhor estratégia, bem como, em muitos casos o que mais resulta é a remixagem (combinação de vários modelos) para se atingir os propósitos educativos.

As tecnologias digitais ao ocuparem um espaço na vida dos jovens deverão ser integradas às metodologias ativas, como fonte de consulta a materiais, para realização de tarefas ou simplesmente um canal de comunicação entre professor-aluno e aluno-aluno. Muitas delas já oferecem a plataforma ideal para a organização didática e ao explorarem o som, o vídeo, a imagem e a animação terminam por atrair a atenção e favorecer uma aprendizagem mais contextualizada, atualizada e lúdica. No entanto, há de se ponderar sempre os riscos no uso destes recursos, além disso, a preocupação em conceber tarefas que exijam a criação (sem que as respostas estejam prontas na internet), e ainda que se esclareçam os perigos das postagens na internet, da importância da análise da informação obtidas online através de uma leitura crítica, entre outros aspectos da cultura digital.

Com planejamento e proposição de tarefas criativas, principalmente aquelas que os alunos sintam que aplicabilidade (ou aproveitamento real) dos resultados, eles se envolvem mais e trabalham de maneira mais árdua para dar respostas criativas. Ao executar uma metodologia ativa, percebe-se um aumento na confiança sobre a aprendizagem de maneira autônoma, uma maior facilidade em pesquisar materiais, descobrir e resolver problemas com maior agilidade. Neste tipo de metodologia os alunos exercitam o trabalho em grupo, a discussão e ao mesmo tempo desenvolvem aprendizagens que nem sempre estão ligados ao conteúdo em si, mas que podem depois ser reaproveitados em outros contextos (ex: gravar um vídeo e editá-lo, melhorar ou cortar uma imagem, produzir um banner, etc.). Em relação a sala de aula invertida, apesar de já existir a um certo tempo, ainda existe muito a explorar e desenvolver, com criatividade e planejamento e integração de novos aplicativos abre-se espaço para novas possibilidades ao desenvolver nos alunos habilidades de ordem superior.

\section{Referências}

BACICH, Lilian; MORAN, José (Orgs.). Metodologias ativas para uma educação inovadora: uma abordagem teórico-prática. Porto Alegre: Penso, 2018.

BERGMANN, J. L.; SAMS, A. Flip your Classroom: reach every student in every class every Day. Eugene: International Society for technology in Education, 2012.

BERGMANN, Jonathan; SAMS, Aaron. Sala de aula invertida: uma metodologia ativa de aprendizagem. Trad. Afonso Celso da Cunha Serra. 1. ed. Rio de Janeiro: LTC, 2016. BOTTENTUIT JUNIOR, J. B. Verificando os Conhecimentos dos Alunos com Tecnologias Digitais: o aplicativo Kahoot. In: Sidcley Cavalcante da Silva. (Org.). Tecnologias Digitais e Aprendizagem Oline. $1^{\circ}$ ed.João Pessoa: Libellus Editorial, 2017, v. , p. 117-137.

CARVALHO, A. A. A. Apps para ensinar e para aprender na era mobile learning. Apps para Dispositivos Móveis. Manual para professores, Formadores e Bibliotecários. Lisboa: Ministério da Educação Direção-geral da Educação, 2015. p. 9-17.

COSTA, M. J. M.; DUAILIBE, R. O.; BOTTENTUIT JUNIOR, J. B. Metodologias Ativas em Sala de Aula: o uso do plickers no ensino de geografia em uma escola da rede pública em São Luís? MA. Revista Tecnologias na Educação, v. 10, p. 1-17, 2018. 
COSTA, M. J. M.; MONTEIRO, J. C. S.; BOTTENTUIT JUNIOR, J. B. Sala de aula invertida, ensino híbrido e metodologias ativas: possibilidades pedagógicas com o Edpuzzle. In: $4^{\circ}$ Encontro sobre Jogos e Mobile Learning, 2018, Coimbra - Portugal. Atas do $4^{\circ}$ Encontro sobre Jogos e Mobile Learning. Coimbra - Portugal: CEIS20, 2018. p. 131-138.

FARDO, M. L. A gamificação aplicada em ambientes de aprendizagem. Revista Novas Tecnologias na Educação - RENOTE, v. 11, p. 1, 2013.

FEITOSA FILHO, J. C.; COSTA, M. J. M.; LIMA, M. S. N. M.; BOTTENTUIT JUNIOR, J. B. Criação, Engajamento e Avaliação em Dispositivos Móveis: potencialidades e contribuições do Nearpod na aprendizagem móvel. Revista Tecnologias na Educação, v. 10, p. 1-16, 2018.

FLIPPED LEARNING NETWORK. Definition of flipped learning. 2014. Disponível em:<http://flippedlearning.org/definition-of-flipped-learning/>. Acesso em: 29 jul. 2019. GOMES, M. P. C.; RIBEIRO, V. M. B.; MONTEIRO, D. M.; LEHER, E. M. T.; LOUZADA, R. C. R. O uso de metodologias ativas no ensino de graduação nas ciências sociais e da saúde - avaliação dos estudantes. Revista Ciência e Educação v. 16, 2010. GOUNARI, P. A democracia na nova era tecnológica. Mangualde: Edições Pedago, 2009.

GUIMARÃES, J. C. F.; SEVERO, E. A. ; SERAFIN, V. F. ; CAPITANIO, R. P. R. . Formação Docente: Uso de Metodologias Ativas Como Processo Inovador de Aprendizagem para o Ensino Superior. In: XVI Mostra de Iniciação Científica, Pósgraduação, Pesquisa e Extensão, 2016, Caxias do Sul. Caxias do Sul: UCS, 2016.

MASSON, T. J.; MIRANDA, L. F. ; MUNHOZ JUNIOR., A. H. ; CASTANHEIRA, A. M. P. . Metodologia de Ensino: Aprendizagem Baseada em Projetos (PBL). In: COBENGE 2012 - XL Congresso Brasileiro de Educação em Engenharia, BelémPará-Brasil. 2012.

MOURA, A. NEARPOD: uma solução integrada para avaliação, apresentação e colaboração. In: CARVALHO, Ana Amélia. Apps para Dispositivos Móveis: Manual para professores, Formadores e Bibliotecários. Lisboa: Ministério da Educação Direçãogeral da Educação, 2015. p. 239-245.

NATIONAL EDUCATION ASSOCIATION. Preparing 21st Century Students for a Global Society: An Educator's Guide to the "Four Cs". 2010. Disponível em: <http://www.nea.org/assets/docs/A-Guide-to-Four-Cs.pdf> Acesso em: 27 jul. 2019.

OTERO-SABORIDO, F., SÁNCHEZ-OLIVER, A., GRIMALDI-PUYANA, M.; ÁLVAREZ-GARCÍA, J. Flipped learning and formative evaluation in higher education, Education + Training, v. $60 \mathrm{n}^{\circ} .5$, pp. 421-430. 2018.

PLUMP, C. M.; LAROSA, J. Using Kahoot! in the Classroom to Create Engagement and Active Learning: A Game-Based Technology Solution for eLearning Novices. Management Teaching Review, Fairfield , Iowa, v. 2, n. 2, p.151-158, 2017.

RIBEIRO, Luis Roberto de Camargo. Aprendizagem baseada em problemas (PBL): uma experiência no ensino superior. São Carlos: Edufscar, 2008.

ROSSASI, L. B.; POLINARSKI, C. A. Reflexões sobre Metodologias para o Ensino de Biologia: uma perspectiva a partir da prática docente. 2011. Disponível em: <http://www.diaadiaeducacao.pr.gov.br/portals/pde/arquivos/491-4.pdf >. Acesso em: 27 jul. 2019.

SANTOS, W. A. C. Desenvolvimento da Sala de Aula Invertida no Ensino Fundamental: um estudo de caso. Dissertação (Mestrado em Educação), Universidade Federal de Alagoas. 2019.

SILVA, T. G.; MÜLLER, M. F. ; BERNARDI, G. . Panorama do Ensino de Engenharia de Software em Cursos de Graduação Focado em Teste de Software: Uma Proposta de 
Aprendizagem Baseada em Jogos. Revista Novas Tecnologias na EducaçãoRENOTE, v. 9, p. 1-10, 2011.

SPAGNOL, C. A formação continuada de professores: o design thinking como perspectiva inovadora e colaborativa na educação básica. (Tese de Doutorado em Educação). Programa de Pós-Graduação em Educação, Porto Alegre: Pontifícia Universidade Católica do Rio Grande do Sul. 2017.

TALBERT, ROBERT. Guia para utilização da aprendizagem invertida no ensino superior. Porto Alegre: Penso, 2019.

ZAINUDDIN, Z.; PERERA C. J. Exploring students' competence, autonomy and relatedness in the flipped classroom pedagogical model, Journal of Further and Higher Education, vol 43: nº1, 115-126. 2019. 